Published in final edited form as:

J Am Chem Soc. 2016 March 23; 138(11): 3687-3693. doi:10.1021/jacs.5b11606.

\title{
Calcium uncaging with visible light
}

\author{
Hitesh K Agarwal ${ }^{1,2}$, Radoslav Janicek ${ }^{3,2}$, San-Hui Chi ${ }^{4}$, Joseph W Perry ${ }^{4}$, Ernst Niggli3,", \\ and Graham CR Ellis-Davies ${ }^{1, *}$
}

${ }^{1}$ Department of Neuroscience, Mount Sinai School of Medicine, New York, NY 10029, USA.

${ }^{3}$ Department of Physiology, University of Bern, Bern CH 3012, Switzerland. ${ }^{4}$ School of Chemistry and Biochemistry, Center for Organic Photonics and Electronics, Georgia Institute of Technology, Atlanta, GA 30332, USA.

\section{Abstract \\ We have designed a nitroaromatic photochemical protecting group that absorbs visible light in the violet-blue range. The chromophore is a dinitro derivative of bisstyrylthiophene (or BIST) that absorbs light very effectively $\left(\varepsilon_{440}=66,000 \mathrm{M}^{-1} \mathrm{~cm}^{-1}\right.$ and two-photon cross section of $350 \mathrm{GM}$ at $775 \mathrm{~nm}$ ). We developed a "caged calcium" molecule by conjugation of BIST to a $\mathrm{Ca}^{2+}$ chelator that upon laser flash photolysis rapidly releases $\mathrm{Ca}^{2+}$ in less than $0.2 \mathrm{~ms}$. Using the patch-clamp method the optical probe, loaded with $\mathrm{Ca}^{2+}$, was delivered into acutely isolated mouse cardiac myocytes, where either one- and two-photon uncaging of $\mathrm{Ca}^{2+}$ induced highly local or cell-wide physiological $\mathrm{Ca}^{2+}$ signaling events.}

\section{Graphical abstract}

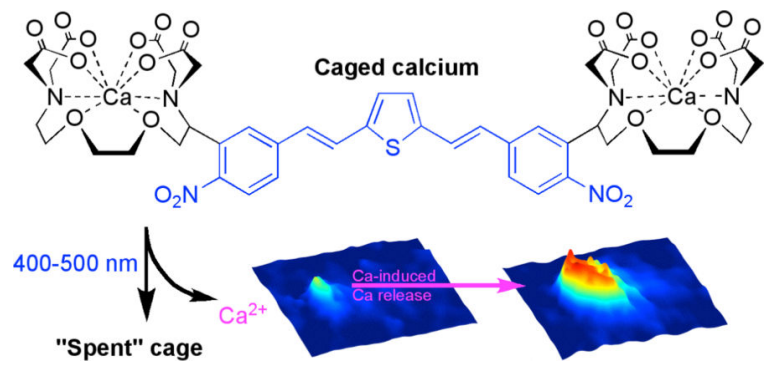

\section{Introduction}

Photochemical uncaging of organic substrates is a valuable optical method that is used in many areas of science ${ }^{1}$. Invented by chemists for organic synthesis in the $1960 \mathrm{~s}^{2}$, it was adopted by physiologists in the $1970 \mathrm{~s}^{3}$ to control the concentration of cellular signaling molecules ${ }^{4}$. Material chemists have also found an important application of this method to

*correspondence graham.davies@mssm.edu or niggli@pyl.unibe.ch.

2 These authors contributed equally to this work.

Supporting information. NMR spectra and HR-MS for all new compounds.

The authors declare no competing financial interest. 
construct high-density micro array chips ${ }^{5}$. Uncaging remains a uniquely powerful way to control the concentration of intracellular calcium ions $\left(\left[\mathrm{Ca}^{2+}\right]_{\mathrm{i}}\right)$, but since covalent bonds cannot be made with ionized calcium, photolysis is normally used to decrease in an irreversible manner the affinity of $\mathrm{Ca}^{2+}$ chelators for the cation ${ }^{6,7}$ (note sodium ${ }^{8}$ and zinc ${ }^{9}$ uncaging use this approach and that other approaches for $\mathrm{Ca}^{2+}$ have been suggested recently $\left.{ }^{10,11}\right)$. We have used the bifurcation of known high affinity tetracarboxylic molecules into known low affinity dicarboxylates for highly efficient, rapid $\mathrm{Ca}^{2+}$ uncaging ${ }^{12-14}$. Because this is the only optical method for creating large changes in $\left[\mathrm{Ca}^{2+}\right]_{\mathrm{i}}$ of 10-100 $\mu \mathrm{M}$, our optical probes have been extensively used for many biochemical and physiological experiments ${ }^{15}$.

The most widely used chromophores for all uncaging experiments are the ortho-nitrobenzyl and ortho-nitroveratryl protecting groups, which absorb light in the near-ultraviolet range but are not efficiently photolyzed by visible light of longer wavelengths. Subsequently several chromophores have been used for uncaging of biological signaling molecules with blue light ${ }^{16-21}$. Photochemical protecting groups sensitive to green light have also been reported ${ }^{22-24}$, but to our knowledge no biological studies have appeared with these probes. Some of these probes are very important additions to the arsenal of caged compounds available for use by biologists, however none of them offer the same generality of carbonheteroatom bond scission that is part of ortho-nitrobenzyl photochemistry.

Extended $\pi$-electron systems have been used to tune the absorption maximum of fluorophores for one- and two-photon (or 1P and 2P) excitation ${ }^{25-29}$. However when these molecules are used for uncaging ${ }^{25,27}$ they do not preserve the generality of simple orthonitrobenzyl groups. Thus, we have taken a step to address this need by creating an orthonitrobenzyl caging chromophore with an absorption maximum that is relatively bathochromic compared to the ortho-nitroveratryl chromophore. The new chromophore, a dinitro derivative of bisstyrylthiophene (or BIST, blue substructure of $\mathbf{1}$ in Fig. 1), has a 1P absorption maximum at $440 \mathrm{~nm}$ (Fig. 2a), and is very sensitive to linear excitation across the 400-500 nm range of the electromagnetic spectrum. Further, it has large $2 \mathrm{P}$ absorption cross-section, of at least $250 \mathrm{GM}$, in the $720-830 \mathrm{~nm}$ range (Fig. 2b). Here we detail the application of the BIST chromophore to the development of a photosensitive, $\mathrm{Ca}^{2+}$-selective chelator based on ethyleneglycoltetraacetic acid (or EGTA) ${ }^{30,31}$, which, with the addition of the cation becomes a caged calcium probe (Fig. 1) that is activated very efficiently by visible light.

\section{Results}

\section{Chemical synthesis}

Concerned about the lipophilic nature of the BIST chromophore, we chose as our first target a symmetrical molecule bearing two EGTA chelators. The synthesis of this molecule (Fig. 1), which we call BIST-2EGTA, started by conversion of 2-nitro-5-bromobenyzaldehyde into the epoxide with carboxymethyl-4-cyanophenylmethylsulfonium trifluoromethanesulfonate in presence of cesium carbonate to give $\mathbf{2}$ in a $74 \%$ yield. The diether backbone of the $\mathrm{Ca}^{2+}$ coordination sphere was created using base-catalyzed ring opening of the epoxide with ethylene glycol to give the desired diol $\mathbf{3}$ in 80\% yield, along 
with $5 \%$ of the other regiomer. The mixture of diols was converted to their dibromides using $\mathrm{Ph}_{3} \mathrm{P}$ and $\mathrm{CBr}_{4}$. From this mixture pure dibromide 4 was easily isolated by flash chromatography and then treated with sodium azide to give $\mathbf{5}$ in $74 \%$ overall yield for the two steps. The vinyl unit was added to the chromophore by treatment of 5 with 2,4,6trivinyl-boroxin pyridine complex and tetrakis(triphenylphosphine)palladium to give 6 in a yield of $73 \%$. The complete chromophore was constructed by Heck coupling of 6 with dibromothiophene to give 7 in $71 \%$ yield. The ethyl ester of BIST-2EGTA was made by reduction of the tetraazide 7 to its tetraamine in $70 \%$ yield, followed by alkylation with ethyl bromoacetate to give octaester $\mathbf{8}$ in $31 \%$ yield. Finally, the esters were hydrolyzed with an excess of $\mathrm{KOH}$ to give the target chelator BIST-2EGTA (1). Importantly, we have found such solutions to be highly stable. Routinely we store all caged compounds at $-40^{\circ} \mathrm{C}$, and solutions of BIST-2EGTA have be found to be stable for more than one year, as judged by HPLC (same single peak). Furthermore, such solutions are equally efficacious when used for uncaging inside cells.

\section{One- and two-photon absorption properties of BIST}

Irradiation of BIST-2EGTA with visible light revealed that the new photosensitive chelator was photolyzed slightly more slowly than DEAC450-Glu (quantum yield $0.39^{32}$ ). Thus, HPLC analysis showed that BIST-2EGTA photolyzed with a quantum yield of photolysis of 0.23 (Supplemental Fig. 1 shows representative HPLC traces). The absorption maximum of BIST was bathochromically shifted when compared to the widely used ortho-nitroveratryl (DM-nitrophen ${ }^{33}$ ) photochemical protecting group (Fig. 2a) such that BIST-2EGTA showed peak absorption at $440 \mathrm{~nm}$ with an extinction coefficient of $66,000 \mathrm{M}^{-1} \mathrm{~cm}^{-1}$. We used the $\mathrm{Z}$-scan method ${ }^{34}$ and $2 \mathrm{P}$-induced fluorescence to determine the $2 \mathrm{P}$ absorption properties of simple BIST derivatives $\mathbf{9}$ and $\mathbf{1 0}$ (Fig. 2b). For simplicity we chose to examine molecules without benzylic substitutions as such functionalities would be photolyzed during such measurements. The simplest dinitro-BIST (9) had a $2 \mathrm{P}$ absorption cross section in DMSO of $740 \mathrm{GM}$ at $775 \mathrm{~nm}$. This chromophore absorbed 2 photons strongly across the $720-900 \mathrm{~nm}$ range (Fig. 2b). A BIST derivative having substituents ortho to both nitro groups (10) showed similar, large $2 \mathrm{P}$ absorption properties, with a maximum $2 \mathrm{P}$ cross section of $350 \mathrm{GM}$ at $775 \mathrm{~nm}$ (Fig. 2b). Note, the effects of aqueous solvent on the $2 \mathrm{P}$ cross section in other reports of similar compounds are modest ${ }^{35}$. The 2 -fold reduction of the $2 \mathrm{P}$ cross section of 9 is probably caused by steric clash between the ortho substituents and the nitro groups twisting the latter out of planarity with the aromatic ring system in compound $\mathbf{1 0 .}$

\section{Calcium binding and release}

Calcium titration of BIST-2EGTA in aqueous solution was used to determine the apparent dissociation constant at various $\mathrm{pH}$ vales. Fig. $2 \mathrm{c}$ shows the increase in fluorescence emission from X-rhod-1 during addition of defined aliquots of $\mathrm{Ca}^{2+}(0.1 \mathrm{mM})$ to a solution of BIST-2EGTA. These data allow the free $\left[\mathrm{Ca}^{2+}\right]$ to be determined as previously described ${ }^{30}$, and showed that the chelator bound $\mathrm{Ca}^{2+}$ with high affinity $\left(\mathrm{K}_{\mathrm{d}} 84 \mathrm{nM}\right.$ at $\mathrm{pH}$ 7.2, $50 \mathrm{nM}$ at $\mathrm{pH} 7.35$ and $19 \mathrm{nM}$ at $\mathrm{pH}$ 7.5). In independent experiments we used $\mathrm{Ca}^{2+}$ selective electrodes to measure to the $\mathrm{K}_{\mathrm{d}}$ and these data gave identical values. The presence of physiological $\mathrm{Mg}^{2+}$ concentrations (i.e. $1 \mathrm{mM}$ ) had no effect on these values. Importantly, 
$\mathrm{Ca}^{2+}$ was shown to be a photoproduct of the BIST-2EGTA:Ca ${ }^{2+}$ complex upon irradiation with visible light. Photolysis of a solution of BIST-2EGTA $85 \%$ saturated with $\mathrm{Ca}^{2+}(1 \mathrm{mM}$ cage with $1.7 \mathrm{mM} \mathrm{Ca}^{2+}$ at $\left.\mathrm{pH} 7.35\right)$ with a blue laser $(473 \mathrm{~nm})$ increased the $\left[\mathrm{Ca}^{2+}\right]_{\text {free }}$ from $0.2 \mu \mathrm{M}$ to $20 \mu \mathrm{M}$ measured with a $\mathrm{Ca}^{2+}$-selective electrode. HPLC analysis showed $50 \%$ of BIST-2EGTA remained in this experiment (Supplemental Fig. 2). The large increase in free $\left[\mathrm{Ca}^{2+}\right]$ is to be expected as iminodiacetic acids are known to have $\mathrm{Ca}^{2+}$ affinity of about 1 $\mathrm{mM}$ in the physiological $\mathrm{pH}$ range ${ }^{36}$. We modeled our reaction with "Patcher's Power Tools" and found that the increase in free $\left[\mathrm{Ca}^{2+}\right]$ must result from a decrease in affinity of approximately 20,000 -fold (i.e. from $50 \mathrm{nM}$ to $1 \mathrm{mM}$ ). It should be noted that the affinities of BIST-2EGTA before and after photolysis are, as expected, the same as the UV-light sensitive $\mathrm{Ca}^{2+}$ cage NP-EGTA ${ }^{30,31}$, a chelator that is structurally identical in terms of $\mathrm{Ca}^{2+}$ binding.

\section{Characterization of dynamic calcium uncaging}

The rate of substrate release is important for many applications of caged compounds, especially those concerned with $\mathrm{Ca}^{2+}$ signaling ${ }^{30}$. Low affinity fluorescent $\mathrm{Ca}^{2+}$ dyes allow the $\left[\mathrm{Ca}^{2+}\right]$ to be measured with temporal fidelity, as the rate-limiting step for equilibration of the dye: $\mathrm{Ca}^{2+}$ complex is determined by the off-rate of the dye ${ }^{37}$. Fluorescence imaging with a confocal microscope in point scan mode revealed that rhod-FF $\left(\mathrm{K}_{\mathrm{d}}=19 \mu \mathrm{M}\right)$ showed a rapid change in signal (exponential time constant of less than $200 \mu \mathrm{s}$ ) when BIST-2EGTA was photolyzed using $2 \mathrm{P}$ excitation at $810 \mathrm{~nm}$ (Fig. 2d).

The widely used ${ }^{15}$ nitroaromatic caged calcium compounds (e.g. DM-nitrophen ${ }^{33}$ or NPEGTA $^{31}$ ) photolyze much more effectively at relatively short wavelengths (e.g. $2 \mathrm{P}$ excitation at $720 \mathrm{~nm}$, or $1 \mathrm{P}$ excitation in the UV-C range) when compared to longer wavelengths (i.e. $>800 \mathrm{~nm}$ for $2 \mathrm{P}$ excitation and $400-500 \mathrm{~nm}$ for $1 \mathrm{P}$ excitation). Thus DM-nitrophen showed a relative 2P-uncaging efficacy of 7.40 for $720 \mathrm{~nm}$ versus $810 \mathrm{~nm}$ (Fig. 2e). Consistent with the $2 \mathrm{P}$ absorption spectrum (Fig. $2 \mathrm{~b}$ ), we found that BIST-2EGTA was equally sensitive to 2P photolysis at these two wavelengths (Fig. 2f). However, when DM-nitrophen was photolyzed under the same resting $\left[\mathrm{Ca}^{2+}\right]_{\text {free }}$ the fluorescence signal from rhod-FF upon $\mathrm{Ca}^{2+}$ release from BIST-2EGTA was about $13.7 \times$ larger than after release from DMnitrophen at $720 \mathrm{~nm}$ (Fig. 2f). Figs. 2e,f also imply BIST is about 100× more effective at 810 $\mathrm{nm}$. Taken together these data show that BIST-2EGTA binds $\mathrm{Ca}^{2+}$ with high affinity, absorbs light strongly and is photolyzed efficiently to create changes in $\left[\mathrm{Ca}^{2+}\right]$ that are potentially useful for physiological studies. We tested such effectiveness in acutely isolated cardiac myocytes.

\section{Two-photon uncaging of $\mathrm{Ca}^{2+}$ : photocontrol of local $\mathrm{Ca}^{2+}$ signaling}

In cardiac myocyte cells a small amount of $\mathrm{Ca}^{2+}$ enters the cytoplasm upon depolarization and initiates $\mathrm{Ca}^{2+}$-induced $\mathrm{Ca}^{2+}$ release from the sarcoplasmic reticulum (SR) store. Such release events can remain highly localized or initiate " $\mathrm{Ca}^{2+}$ waves" that propagate through the cell ${ }^{38}$. These signals were recorded as confocal line scan $(x, t)$ images, where the vertical axis shows the spatial dimension while the horizontal axis represents time. Individual myocytes were loaded with BIST-2EGTA $(0.5$ or $1 \mathrm{mM})$ and rhod-2 $(0.1 \mathrm{mM})$ or X-rhod-5F $(0.1 \mathrm{mM})$ via a patch pipette. $2 \mathrm{P}$ excitation at $810 \mathrm{~nm}$ produced localized $\mathrm{Ca}^{2+}$ transients 
that were considerably larger (Fig. 3a) than those produced by BIST-2EGTA photolysis in caffeine-treated cells (Fig. 3b). Caffeine completely unloads $\mathrm{Ca}^{2+}$ from the SR, so allows the pure photolytic $\mathrm{Ca}^{2+}$ signal to be detected. The difference between the two signals therefore reflects the biological $\mathrm{Ca}^{2+}$ release from the SR. Uncaging for longer periods triggered intracellular $\mathrm{Ca}^{2+}$ "mini-waves" that caused separate release events a small distance from the uncaging site (Fig. 3c). In contrast, we also found that very brief irradiation of BIST-2EGTA for $1 \mathrm{~ms}$ could initiate highly localized $\mathrm{Ca}^{2+}$-induced $\mathrm{Ca}^{2+}$ release from the SR (Fig. 3d,e). Previously we have found that with DM-nitrophen any $\mathrm{Ca}^{2+}$ release from the SR always required substantially longer flash durations (ca. $50 \mathrm{~ms}$ ) ${ }^{13,14,39-41}$.

\section{Photochemically initiated intracellular $\mathrm{Ca}^{2+}$ waves using visible light and 2P excitation}

We found that $2 \mathrm{P}$ excitation of BIST-2EGTA could also initiate strong $\mathrm{Ca}^{2+}$-induced $\mathrm{Ca}^{2+}$ release processes that extended considerable distances from the uncaging point. In Fig. $4 \mathrm{a}$ we show using line scan fluorescence imaging that $2 \mathrm{P}$ excitation can produce such $\mathrm{Ca}^{2+}$ waves that propagate rapidly in both directions Note that such line scan imaging $(\mathrm{x}, \mathrm{t})$ has the advantage of a higher imaging rate compare to full frame $(\mathrm{x}, \mathrm{y}, \mathrm{t})$, but conveys limited spatial information about the entire cardiac cell. Thus we combined visible light uncaging with full frame imaging which allowed us to produce striking $\mathrm{Ca}^{2+}$ waves that propagated throughout the cell (Fig. 4b). These signals are similar to those reported in many physiological studies of cardiac myocytes (reviewed in ${ }^{38,42}$ ). It should be noted there was negligible optical cross talk between the 810-nm 2P uncaging and 561-nm confocal imaging lasers under these conditions. Specifically, imaging at $561 \mathrm{~nm}$ was performed with energies $0.1 \%$ of those used for photolysis with $405 \mathrm{~nm}$. Further, irradiation with EGTA in place of BIST-2EGTA (Supplementary Fig. 3), or without prior chelator loading with $\mathrm{Ca}^{2+}$, did not produce any $\mathrm{Ca}^{2+}$ waves. Importantly, cells displayed normal excitation-contraction coupling, as seen in the cellular $\mathrm{Ca}^{2+}$ transient preceding photolytic $\mathrm{Ca}^{2+}$ release, implying that BIST-2EGTA is nontoxic inside cells (not shown).

\section{Discussion}

We have developed an extended $\pi$-electron nitrobenzyl caging chromophore, which we call "BIST", that is photolyzed efficiently with visible light in the violet-blue region. Several recently developed caging chromophores are photolyzed in this range ${ }^{1}$, however these cages are somewhat limited by the photosolvolysis reactions they use $\mathrm{e}^{32}$. In contrast, the intramolecular photoredox reaction used by BIST can be used for carbon-amine and carbonether photoscission ${ }^{43}$ (see Supplementary Fig. 4 where we show that amines and alcohols are uncaged cleanly from BIST). We took advantage of this unique feature by using BIST to cleave a C-N tertiary amine bond at the heart of the $\mathrm{Ca}^{2+}$-selective chelator EGTA to develop a caged $\mathrm{Ca}^{2+}$ probe that is photolyzed with visible light, and thus fabricate a caged $\mathrm{Ca}^{2+}$ probe with distinctive optical properties (Table 1).

Originally ultraviolet lasers were used to photolyze ortho-nitrobenzyl caged compounds rapidly $^{44,45}$. Subsequently flash lamps with a filtered output were used ${ }^{46,47}$. However, blue lasers are now much more widely available than either of these light sources, being standard on all confocal microscopes and used extensively for "optogenetics" 48 . Therefore the 
development of a new caging chromophore that is sensitive and efficiently photolyzed in this region of the electromagnetic spectrum is a potentially useful addition to the optical toolkit available to chemists and biologists. Having an extinction coefficient of $66,000 \mathrm{M}^{-1} \mathrm{~cm}^{-1}$ (c.f. fluorescein ${ }^{49}$ that has an extinction coefficient of $77,000 \mathrm{M}^{-1} \mathrm{~cm}^{-1}$ ), it absorbs light very efficiently in the blue region, a property which is unique compared to other caged $\mathrm{Ca}^{2+}$ probes (Table 1). Furthermore, $2 \mathrm{P}$ uncaging is also considerably more efficient than the ortho-nitroveratryl caging chromophore (Fig. 2), suggesting that direct attachment of a large $2 \mathrm{P}$ antenna to the caged substrate, rather than relying on resonance $\operatorname{transfer}^{50}$, can be very effective for photorelease. Typically most extended $\pi$-electron systems examined by material chemists for $2 \mathrm{P}$ absorption are electron rich, with symmetrical diamino derivatives being very popular ${ }^{51}$. It is interesting that our electron deficient dinitro-BIST derivatives have similar 2P absorption properties to comparable diamino derivatives ${ }^{52}$, suggesting that polarization per se is the crucial property for chromophores in this context.

\section{Conclusions}

BIST is a new photochemical protecting group that absorbs visible light efficiently. Beyond our initial application to $\mathrm{Ca}^{2+}$ uncaging, since BIST uses similar photochemistry to the widely used ortho-nitrobenzyl and ortho-nitroveratryl chromophores, we tentatively suggest BIST could be used to uncage the widest variety of functionalities. Our current data show that BIST-2EGTA is an exceptionally photosensitive caged $\mathrm{Ca}^{2+}$ probe (Table 1), making superb use of both $1 \mathrm{P}$ and $2 \mathrm{P}$ excitation. Importantly, BIST-2EGTA is photolyzed by blue light and the wide availability of light sources in this region could make $\mathrm{Ca}^{2+}$ uncaging experiments attractive to many more laboratories.

\section{Methods}

\section{Chemical synthesis}

See supplement for full methods and analytic details.

\section{Calcium affinity}

The $\mathrm{Ca}^{2+}$ affinity of BIST-2EGTA was measured as previously described by us for NPEGTA $^{31}$. Briefly, a homemade $\mathrm{Ca}^{2+}$-selective electrode was made using ETH-129. To a solution of BIST-2EGTA $(0.5-1.0 \mathrm{mM})$ in HEPES $(10 \mathrm{mM})$ and $\mathrm{KCl}(100 \mathrm{mM})$ was added incremental amounts $(0.1 \mathrm{mM})$ of $\mathrm{CaCl}_{2}$ and the change in $\left[\mathrm{Ca}^{2+}\right]_{\text {free }}$ was measured. Scatchard analysis of such titrations revealed that at $\mathrm{pH} 7.2$ the $\mathrm{K}_{\mathrm{d}}$ was $82 \mathrm{nM}, 50 \mathrm{nM}$ at $\mathrm{pH}$ 7.35 and $19 \mathrm{nM}$ at $\mathrm{pH}$ 7.5. In separate experiments we also used changes in fluorescence from X-rhod-1 to measure the $\left[\mathrm{Ca}^{2+}\right]_{\text {free }}$. Values for the $\mathrm{K}_{\mathrm{d}}$ using these methods were identical. Using homemade electrodes we found that the $\left[\mathrm{Ca}^{2+}\right]_{\text {free }}$ of a solution of BIST-2EGTA $(1 \mathrm{mM})$ with $1.7 \mathrm{mM} \mathrm{CaCl}_{2}$ increased from $0.2 \mu \mathrm{M}$ to $20 \mu \mathrm{M}$ when $50 \%$ of the caged compound was photolyzed in a quartz cuvette with a 473nm-laser. Patcher's Power Tools (MPI for Biophysical Chemistry, Gottingen web site) allowed us to model this reaction to account for the change if $\left[\mathrm{Ca}^{2+}\right]_{\text {free }}$ showing the affinity for Ca must be $1 \mathrm{mM}$. 


\section{Quantum yield of photolysis}

The quantum yield of photolysis of BIST-2EGTA was measured as before ${ }^{31,32}$. Briefly, solutions of BIST-2EGTA and DEAC450-Glu, each with an optical density of 0.4 at $410 \mathrm{~nm}$, were photolyzed with a $410 \mathrm{~nm}$ laser. The time-course of photolysis was followed by HPLC analysis. Each time point was analyzed thrice and the photolysis of each compound was also performed three times. The HPLC showed that the rate of photolysis of BIST-2EGTA was $60 \%$ of DEAC450-Glu with a 410-nm laser, implying a quantum yield of 0.23 .

\section{P absorption cross-section}

The $2 \mathrm{P}$ absorption cross-section, $\delta$ (in GM $=1 \times 10^{-50} \mathrm{~cm}^{4} \mathrm{~s}_{\text {molecules }}{ }^{-1}$ photon ${ }^{-1}$ ), of the compounds examined was measured in the 730-930 nm wavelength range. We used the $2 \mathrm{P}-$ induced fluorescence (2PF) method ${ }^{53}$ using $5-n s, 10-\mathrm{Hz}$ pulses (compounds 10a,b) and the z-scan technique using $60-\mathrm{fs}, 1-\mathrm{kHz}$ pulses (compound 9). In 2PF experiment, an optical parametric oscillator laser (Spectra Physics, premiScan) pumped by a Q-switched Nd:YAG laser (Spectra Physics, Quanta-Ray Pro-250). The measurements were conducted in a regime where the fluorescence signal showed a quadratic dependence on the intensity of the excitation beam. The fluorescence signal was collected by a lens and transferred via a fiber to a spectrometer (HORIBA Scientific, iHR320) with a CCD camera (HORIBA Scientific, Synapse). Coumarin 485 ( ref $^{54}$, Sigma-Aldrich), rhodamine B, and bisstyrylbenzene (compound $8 \mathrm{in}^{55}$ ), whose $2 \mathrm{P}$ properties have been well characterized in methanol, were used as the references in 2PF measurements. The samples were prepared in DMSO (SigmaAldrich, Spectrophotometric grade) at a concentration of $3-8 \times 10^{-4} \mathrm{M}$ and the optical pathlength of sample cuvettes for $2 \mathrm{PF}$ measurements was $1 \mathrm{~cm}$. For z-scan measurements ${ }^{56}$, an optical parametric amplified laser (Spectra Physics, TOPAS) pumped by a mode-locked Ti:sapphire regenerative amplifier system (Spectra Physics, Solstice) was used as the excitation source. The excitation beam for z-scan is spatially-filtered as a near Gaussian beam with $\mathrm{M}^{2}<1.1$ and waist $\omega\left(\mathrm{HW}_{1 / \mathrm{e} 2}\right) \sim 40 \mu \mathrm{m}$. The excitation irradiance ranged from $50-150 \mathrm{GW} / \mathrm{cm}^{2}$. The samples were prepared in DMSO (ca. $2 \mathrm{mM}$ ) and the optical pathlength of sample cuvettes for z-scan measurements was $1 \mathrm{~mm}$.

\section{Laser flash photolysis in droplets}

A mode-locked Ti:sapphire laser (Mira 9000F, Coherent, Santa Clara, CA, USA) pumped by $8 \mathrm{~W}$ solid-state Verdi V-8 (Coherent) was used for 2P excitation of BIST-2EGTA or DMnitrophen. Wavelength of the laser was set to 720 or $810 \mathrm{~nm}$ with pulse duration of $\sim 120 \mathrm{fs}$. Power of the laser was adjusted by neutral density and polarizing filters and was measured at the objective focal plane by a power meter (PM200 with sensor S170C, Thorlabs, Newton, New Jersey, USA). The laser beam was guided to the SIM scanner of the confocal microscope (Fluoview 1000, Olympus, Volketswil, Switzerland) operating in single point excitation mode simultaneously with the main scanner. The photolysis period was 1 or 20 ms and the duration was controlled by an electronic shutter LS3 (Vincent Associates, Rochester, NY, USA) and triggered by the confocal microscope. The main scanner of confocal microscope was operating in line scan mode. To record changes in $\mathrm{Ca}^{2+}$ concentration fluo-3, rhod-2 (both Biotium Inc., Hayward, CA, USA), X-rhod-5F (Life Technologies) or rhod-FF (Teflabs, Austin, TX, USA) were excited at 473 or $561 \mathrm{~nm}$, 
respectively. Solutions used for droplet experiments were composed of (mM): for Fig. 2d: 1 BIST-2EGTA, 0.1 rhod-FF, $2 \mathrm{CaCl}_{2}, 100 \mathrm{KCl}, 10 \mathrm{HEPES}, \mathrm{pH}=7.80$; for Fig. 2f: 1 BIST-2EGTA, 0.1 rhod-FF, $2 \mathrm{CaCl}_{2}, 100 \mathrm{KCl}, 10 \mathrm{HEPES}, \mathrm{pH}=8.0$; for Fig. 2e: 2 DMnitrophen, $0.5 \mathrm{CaCl}_{2}$, 0.1 fluo-3, $1 \mathrm{GSH}, 5 \mathrm{~K}_{2} \mathrm{ATP}, 10 \mathrm{HEPES}, 20 \mathrm{TEA}-\mathrm{Cl}, 120 \mathrm{~L}$-Aspartic acid, $120 \mathrm{CsOH}, \mathrm{pH}=7.20$; for Fig. 2f: 2 DM-nitrophen, $2 \mathrm{CaCl}_{2}, 0.1$ rhod-FF, $100 \mathrm{KCl}, 10$ HEPES, pH=7.20. Recorded images were analyzed in MATLAB (MathWorks, Inc., Natick, MA, USA) and Igor Pro (WaveMetrics, Inc., Portland, OR, USA).

\section{Laser flash photolysis in cardiac myocytes}

Cardiac ventricular myocytes were isolated from C57Bl/6 mice as described before ${ }^{57}$. Myocytes were whole-cell patch-clamped at a resting potential $-80 \mathrm{mV}$. A train of five to ten pre-pulses from -40 to $0 \mathrm{mV}$ in the presence of $100 \mathrm{nM}$ isoproterenol was applied to load the sarcoplasmic reticulum with $\mathrm{Ca}^{2+}$. A photolytic pulse with a duration of 1-100 ms was applied 1-3 s after last conditioning pulse to release $\mathrm{Ca}^{2+}$ from BIST-2EGTA. For 2P photolysis we used a Ti:sapphire laser with a wavelength of $810 \mathrm{~nm}$, and for single photon photolysis we used a UV DPSS laser with wavelength $405 \mathrm{~nm}$. Both laser beams were guided to the SIM scanner and data acquisition was the same as described above. Myocytes were placed in a recording chamber in external bath solution containing (mM): $140 \mathrm{NaCl}, 5$ $\mathrm{KCl}, 1 \mathrm{CsCl}, 1.8 \mathrm{CaCl}_{2}, 0.5 \mathrm{BaCl}_{2}, 10$ HEPES, 10 glucose, $\mathrm{pH}=7.40$. Pipettes were filled with internal solution containing (mM): for Figs. 3a-e, 4a: 0.5 BIST-2EGTA, $0.8 \mathrm{CaCl}_{2}, 0.1$ rhod-2, 1 GSH, $4 \mathrm{~K}_{2}$ ATP, $5 \mathrm{MgCl}_{2}$, 10 HEPES, 20 TEA-Cl, 120 L-Aspartic acid, 120 $\mathrm{CsOH}, 8 \mathrm{NaCl}$, $\mathrm{pH}=7.50$; for Fig. 4b: 1 BIST-2EGTA, $1.5 \mathrm{CaCl}_{2}$, $0.1 \mathrm{X}$-rhod-5F, $1 \mathrm{GSH}, 5$ $\mathrm{K}_{2} \mathrm{ATP}, 10$ HEPES, 20 TEA-Cl, 120 L-Aspartic acid, $120 \mathrm{CsOH}, 8 \mathrm{NaCl}, \mathrm{pH}=7.40$. Images in Figs. 3a-e, 4a were normalized, filtered with Gaussian (kernel [5 5]) and Wiener filters (kernel [10 10]) and smoothed by cubic spline ( $\mathrm{p}=0.5$ in MATLAB "caps" function). Experiments were performed at room temperature. All recorded images were processed and analyzed in MATLAB, imageJ and Igor Pro.

\section{Supplementary Material}

Refer to Web version on PubMed Central for supplementary material.

\section{Acknowledgments}

This work was supported by grants from the US NIH (GM053395 and NS069720) to GCRE-D, the AFOSR MURI (FA9550-10-10558) to JWP, and the Swiss National Science Foundation (31-156375 and the Microscopy Imaging Center, or "MIC") to EN. We would like to thank Drs. Simon Langenegger and Robert Häner for their help.

GED conceived of the project, supervised it in its entirety, and wrote the paper. HKA synthesized and characterized the chemical compounds. RJ performed the 2-photon uncaging and physiological studies. SHC measured the 2photon cross sections. All authors commented on the paper and approved the final submitted version.

\section{References}

1. Brieke C, Rohrbach F, Gottschalk A, Mayer G, Heckel A. Angew Chem Int Edit. 2012; 51:84468476.

2. Barltrop JA, Plant PJ, Schofield P. Chem. Commun. 1966:822-823.

3. Kaplan JH, Forbush B, Hoffman JF. Biochemistry. 1978; 17:1929-1935. [PubMed: 148906]

4. Ellis-Davies GCR. Nat Methods. 2007; 4:619-628. [PubMed: 17664946] 
5. McGall GH, Barone AD, Diggelmann M, Fodor SPA, Gentalen E, Ngo N. J. Am. Chem. Soc. 1997; 119:5081-5090.

6. Adams SR, Tsien RY. Annu Rev Physiol. 1993; 55:755-784. [PubMed: 8466191]

7. Ellis-Davies GCR. Methods Enzymol. 2003; 360:226-238. [PubMed: 12622152]

8. Warmuth R, Grell E, Lehn JM, Bats JW, Quinkert G. Helv Chim Acta. 1991; 74:671-681.

9. Basa PN, Antala S, Dempski RE, Burdette SC. Angew Chem-Int Ed. 2015; 54:13027-13031.

10. Wu L, Dai Y, Marriott G. Org Lett. 2011; 13:2018-2021. [PubMed: 21417245]

11. Li D, Hérault K, Isacoff EY, Oheim M, Ropert N. J Physiol (Lond). 2012; 590:855-873. [PubMed: 22219341]

12. Ellis-Davies GCR, Kaplan JH, Barsotti RJ. Biophys J. 1996; 70:1006-1016. [PubMed: 8789118]

13. DelPrincipe F, Egger M, Ellis-Davies GC, Niggli E. Cell Calcium. 1999; 25:85-91. [PubMed: 10191963]

14. Momotake A, Lindegger N, Niggli E, Barsotti RJ, Ellis-Davies GC. Nat Methods. 2006; 3:35-40. [PubMed: 16369551]

15. Ellis-Davies GCR. Chem Rev. 2008; 108:1603-1613. [PubMed: 18447376]

16. Amatrudo JM, Olson JP, Agarwal HK, Ellis-Davies GCR. Eur J Neurosci. 2015; 41:5-16. [PubMed: 25471355]

17. Chiu CQ, Lur G, Morse TM, Carnevale NT, Ellis-Davies GCR, Higley MJ. Science. 2013; 340:759-762. [PubMed: 23661763]

18. Rial Verde EM, Zayat L, Etchenique R, Yuste R. Front. Neural Circuits. 2008; 2:2. [PubMed: 18946542]

19. Olson JP, Banghart MR, Sabatini BL, Ellis-Davies GCR. J Am Chem Soc. 2013; 135:1594815954. [PubMed: 24117060]

20. Priestman MA, Shell TA, Sun L, Lee H-M, Lawrence DS. Angew Chem Int Edit. 2012; 51:76847687.

21. Fournier L, Gauron C, Xu L, Aujard I, Le Saux T, Gagey-Eilstein N, Maurin S, Dubruille S, Baudin JB, Bensimon D, Volovitch M, Vriz S, Jullien L. ACS Chem Biol. 2013; 8:1528-1536. [PubMed: 23651265]

22. Goswami PP, Syed A, Beck CL, Albright TR, Mahoney KM, Unash R, Smith EA, Winter AH. J Am Chem Soc. 2015; 137:3783-3786. [PubMed: 25751156]

23. Rubinstein N, Liu P, Miller EW, Weinstain R. Chem Commun. 2015; 51:6369-6372.

24. Umeda N, Takahashi H, Kamiya M, Ueno T, Komatsu T, Terai T, Hanaoka K, Nagano T, Urano Y. ACS Chem Biol. 2014; 9:2242-2246. [PubMed: 25140990]

25. Zhou W, Kuebler SM, Braun KL, Yu T, Cammack JK, Ober CK, Perry JW, Marder SR. Science. 2002; 296:1106-1109. [PubMed: 12004126]

26. Hara K, Sato T, Katoh R, Furube A, Ohga Y, Shinpo A, Suga S, Sayama K, Sugihara H, Arakawa H. J. Phys. Chem. B. 2003; 107:597-606.

27. Gug S, Bolze F, Specht A, Bourgogne C, Goeldner M, Nicoud J-F. Angew Chem Int Edit. 2008; 47:9525-9529.

28. Albota M, Beljonne D, Bredas J, Ehrlich J, Fu J, Heikal A, Hess S, Kogej T, Levin M, Marder S, McCord-Maughon D, Perry J, Rockel H, Rumi M, Subramaniam C, Webb W, Wu X, Xu C. Science. 1998; 281:1653-1656. [PubMed: 9733507]

29. Reinhardt B, Brott L, Clarson S, Dillard A, Bhatt J, Kannan R, Yuan L, He G, Prasad P. Chem Mater. 1998; 10:1863-1874.

30. Ellis-Davies GCR, Barsotti RJ. Cell Calcium. 2006; 39:75-83. [PubMed: 16303177]

31. Ellis-Davies GCR, Kaplan JH. Proc Natl Acad Sci U S A. 1994; 91:187-191. [PubMed: 8278362]

32. Olson JP, Kwon HB, Takasaki KT, Chiu CQ, Higley MJ, Sabatini BL, Ellis-Davies GCR. J Am Chem Soc. 2013; 135:5954-5957. [PubMed: 23577752]

33. Kaplan JH, Ellis-Davies GCR. Proc Natl Acad Sci U S A. 1988; 85:6571-6575. [PubMed: 3137570]

34. Thorley KJ, Hales JM, Kim H, Ohira S, Bredas JL, Perry JW, Anderson HL. Chemistry-a European Journal. 2013; 19:10370-10377. 
35. Woo HY, Liu B, Kohler B, Korystov D, Mikhailovsky A, Bazan GC. J Am Chem Soc. 2005; 127:14721-14729. [PubMed: 16231926]

36. Martell, AE.; Smith, RM. Critical Stability Constants. Vol. 1. New York: Plenum; 1974. p. 139-199.

37. Higley MJ, Sabatini BL. Neuron. 2008; 59:902-913. [PubMed: 18817730]

38. Niggli E. Annu Rev Physiol. 1999; 61:311-335. [PubMed: 10099691]

39. Lipp P, Niggli E. J Physiol. 1998; 508(Pt 3):801-809. [PubMed: 9518734]

40. Lindegger N, Niggli E. J Physiol. 2005; 565:801-813. [PubMed: 15774509]

41. Ogrodnik J, Niggli E. J Physiol (Lond). 2010; 588:225-242. [PubMed: 19900959]

42. Cheng H, Lederer WJ. Physiol Rev. 2008; 88:1491-1545. [PubMed: 18923188]

43. Binkley, RW.; Flechtner, TW. Synthetic Organic Photochemistry. Horspool, WM., editor. Plenum: New York and London; 1984. p. 375-423.

44. McCray JA, Herbette L, Kihara T, Trentham DR. Proc Natl Acad Sci U S A. 1980; 77:7237-7241. [PubMed: 6938971]

45. Goldman YE, Hibberd MG, McCray JA, Trentham DR. Nature. 1982; 300:701-705. [PubMed: 7177194]

46. Rapp G, Poole KJV, Maeda Y, Ellis-Davies GCR, Kaplan JH, Mccray J, Goody RS. Berichte Der Bunsen-Gesellschaft-Physical Chemistry Chemical Physics. 1989; 93:410-415.

47. Nerbonne JM, Richard S, Nargeot J, Lester HA. Nature. 1984; 310:74-76. [PubMed: 6330568]

48. Gradinaru V, Thompson KR, Zhang F, Mogri M, Kay K, Schneider MB, Deisseroth K. J Neurosci. 2007; 27:14231-14238. [PubMed: 18160630]

49. Sjoback R, Nygren J, Kubista M. Spectrochimica Acta Part a-Molecular and Biomolecular Spectroscopy. 1995; 51:L7-L21.

50. Cueto Diaz EJ, Picard S, Chevasson V, Daniel J, Hugues V, Mongin O, Genin E, Blanchard-Desce M. Org Lett. 2015; 17:102-105. [PubMed: 25522917]

51. Rumi M, Barlow S, Wang J, Perry JW, Marder SR. Adv Polym Sci. 2008; 213:1-95.

52. Zheng S, Beverina L, Barlow S, Zojer E, Fu J, Padilha LA, Fink C, Kwon O, Yi Y, Shuai Z, Van Stryland EW, Hagan DJ, Bredas JL, Marder SR. Chem Commun (Camb). 2007:1372-1374. [PubMed: 17377686]

53. Pond SJK, Rumi M, Levin MD, Parker TC, Beljonne D, Day MW, Bredas JL, Marder SR, Perry JW. Journal of Physical Chemistry A. 2002; 106:11470-11480.

54. Makarov NS, Drobizhev M, Rebane A. Optics Express. 2008; 16:4029-4047. [PubMed: 18542501]

55. Rumi M, Ehrlich JE, Heikal AA, Perry JW, Barlow S, Hu ZY, McCord-Maughon D, Parker TC, Rockel H, Thayumanavan S, Marder SR, Beljonne D, Bredas JL. J. Am. Chem. Soc. 2000; 122:9500-9510.

56. Powell CE, Morrall JP, Ward SA, Cifuentes MP, Notaras EGA, Samoc M, Humphrey MG. J. Am. Chem. Soc. 2004; 126:12234-12235. [PubMed: 15453734]

57. Ullrich ND, Fanchaouy M, Gusev K, Shirokova N, Niggli E. Am J Physiol Heart Circ Physiol. 2009; 297:H1992-H2003. [PubMed: 19783774]

58. Adams SR, Kao JPY, Grynkiewicz G, Minta A, Tsien RY. J Am Chem Soc. 1988; 110:3212-3220.

59. Adams SR, Lev-Ram V, Tsien RY. Chem Biol. 1997; 4:867-878. [PubMed: 9384535] 

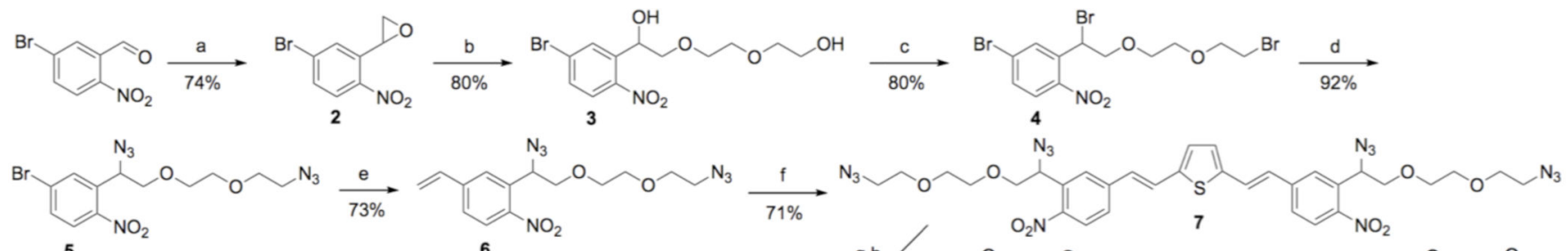

6
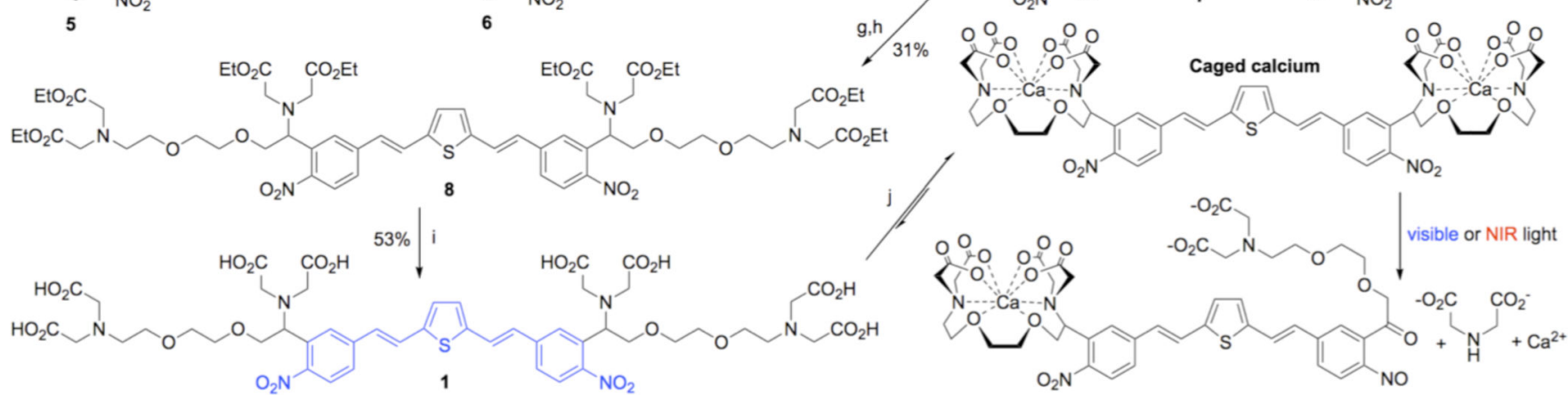

Figure 1. Synthesis of BIST-2EGTA

Reagents and conditions: (a) Carboxymethyl-4-cyanophenylmethylsulfonium trifluoromethanesulfonate, $\mathrm{Cs}_{2} \mathrm{CO}_{3}$, THF; (b) diethylene glycol, $\mathrm{NaH}$; (c) $\mathrm{CBr}_{4}, \mathrm{PPh}_{3}$, DCM; (d) $\mathrm{NaN}_{3}$, Nal, DMF; (e) $\mathrm{Pd}\left(\mathrm{PPh}_{3}\right)_{4}$, 2,4,6-trivinyl-boroxin pyridine complex, $\mathrm{K}_{2} \mathrm{CO}_{3}$, DME, $\mathrm{H}_{2} \mathrm{O}$; (f) dibromothiophene, $\mathrm{Pd}(\mathrm{OAc})_{2}$, LiCI, TBACI, $\mathrm{NaHCO}_{3}$, DMF; (g) $\mathrm{PPh}_{3}$, dioxane, $\mathrm{NaOH}$ (aq); (h) $\mathrm{BrCH}_{2} \mathrm{COOEt}$, pentamethylpiperidine, acetonitrile; (i) $\mathrm{KOH}$, $\mathrm{MeOH}$ (note for clarity the countercation is not shown); (j) $\mathrm{CaCl}_{2}$ in $\mathrm{H}_{2} \mathrm{O}$ (note for clarity the ionic valence and counterion are not depicted). 


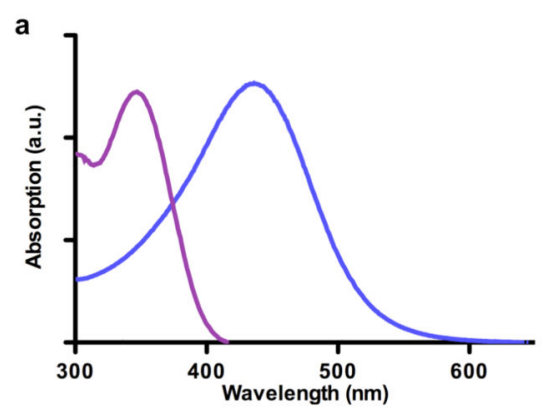

b

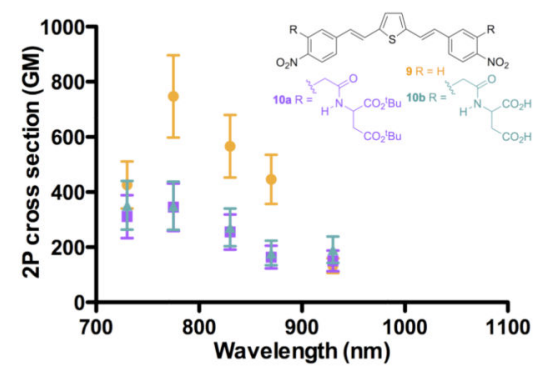

d

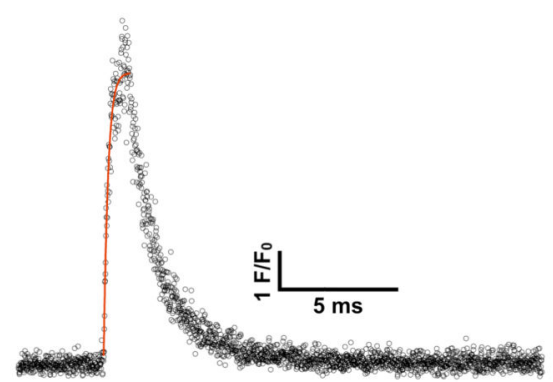

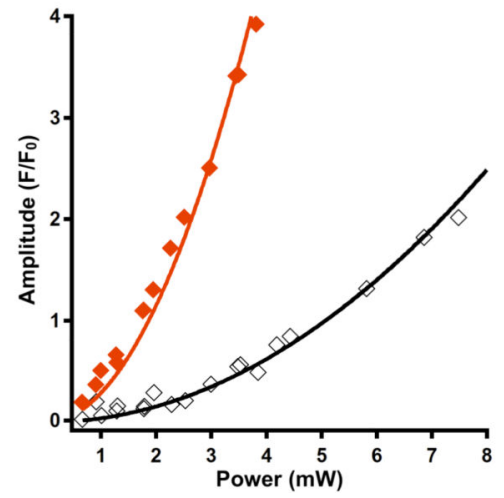
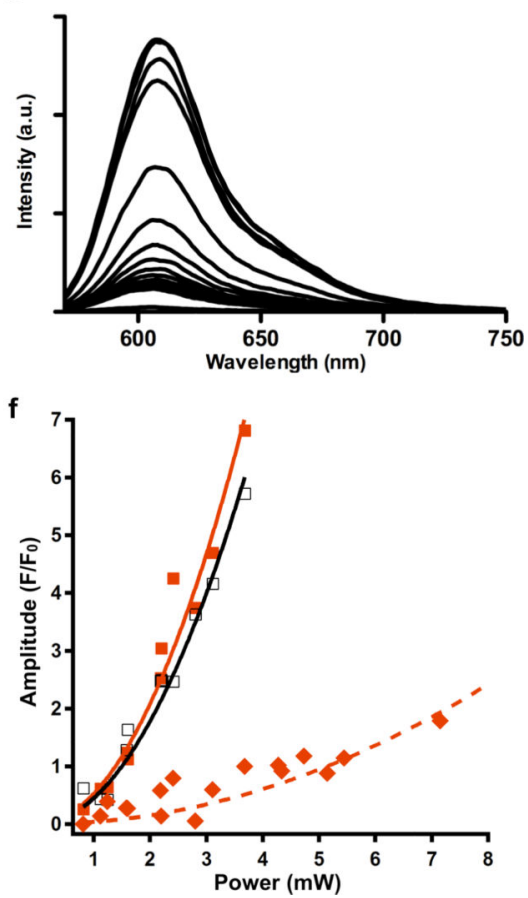

Figure 2. Photochemical characterization of BIST-2EGTA

Nonlinear absorption properties of BIST derivatives were measured using the z-scan technique or by $2 \mathrm{P}$ fluorescence emission. Rapid changes in $\left[\mathrm{Ca}^{2+}\right]_{\text {free }}$ were monitored in point scan mode (10 $\mu$ s per pixel) or in bidirectional line scanning mode ( $244 \mu$ s per line) using laser-scanning confocal microscopy at 561 or $473 \mathrm{~nm}$ after $2 \mathrm{P}$ photolysis with a modelocked Ti:sapphire laser tuned to 810 or $720 \mathrm{~nm}$. (a) Absorption spectra of the BIST-2EGTA (blue) and ortho-nitroveratryl (DM-nitrophen, violet) chromophores showing their relative 1P maxima. (b) 2P absorption spectra of BIST derivatives. Compound 9 had a $2 \mathrm{P}$ absorption maximum in DMSO of $740 \mathrm{GM}$ at $775 \mathrm{~nm}$ (orange). Each data point is an average of 5 or 6 measurements. Compounds 10a (R purple) and $\mathbf{1 0 b}$ (R green) have a $2 \mathrm{P}$ absorption maximum in DMSO of $350 \mathrm{GM}$ at $775 \mathrm{~nm}$. All points are shown $\pm \mathrm{SD}$. (c) Example of Ca titration of a solution of BIST-2EGTA with X-rhod-1. Addition of $0.1 \mathrm{mM}$ amount of $\mathrm{CaCI}_{2}$ to a solution of BIST-2EGTA $(0.5 \mathrm{mM})$ at $\mathrm{pH} 7.2$ with $\mathrm{KCI}(100 \mathrm{mM})$ showed the chelator had a high prephotolysis affinity for $\mathrm{Ca}^{2+}$. (d) 2P uncaging of BIST-2EGTA produced a rapid increase in $\mathrm{Ca}$ monitored by point scan confocal imaging using rhod-FF. The exponential time-constant for the fluorescence increase was $164 \mu$ s. (e) The relative efficacy of $2 \mathrm{P}$ uncaging of DM-nitrophen at 810 and $720 \mathrm{~nm}$ was determined by monitoring the photoreleased $\mathrm{Ca}^{2+}$ during a power train at these two wavelengths. Both wavelengths showed a quadratic dependence on incident power, and release was $7.4 \pm 0.23$ times more effective at $720 \mathrm{~nm}$ (closed red diamonds) compared to $810 \mathrm{~nm}$ (open black diamonds). fluo-3 was used to monitor $\mathrm{Ca}^{2+}$ release. (f) $\mathrm{Ca}^{2+}$ release from BIST-2EGTA:Ca ${ }^{2+}$ complex at 810 and $720 \mathrm{~nm}$ was determined by monitoring the fluorescence signal from rhod-FF during a power train at these two wavelengths (810, open black squares; 720 closed red squares). The increase in fluorescence showed a quadratic dependence on incident power and was equally effective at both wavelengths. An identical power train was also used for 
photolysis of DM-nitrophen (720, closed red diamonds). The resting $\left[\mathrm{Ca}^{2+}\right]_{\text {free }}$, the $\mathrm{Ca}^{2+}{ }_{-}$ bound, and $\mathrm{Ca}^{2+}$-free indicator concentrations were the same for both caged calcium compounds. 
a

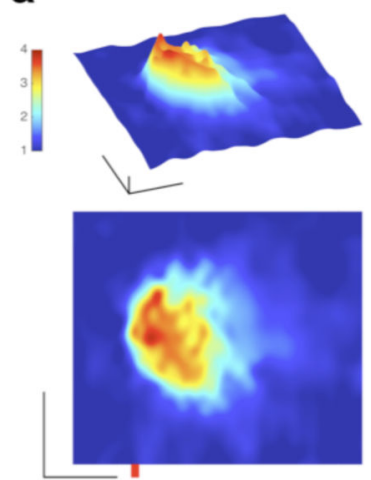

b
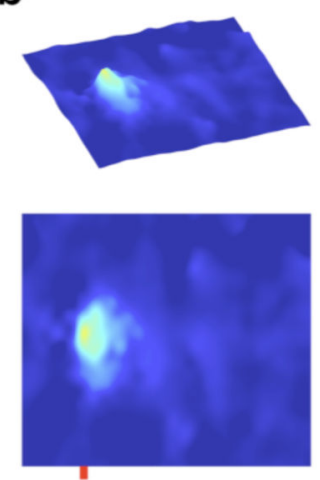

C
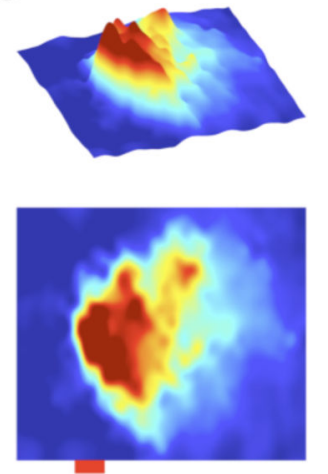

d
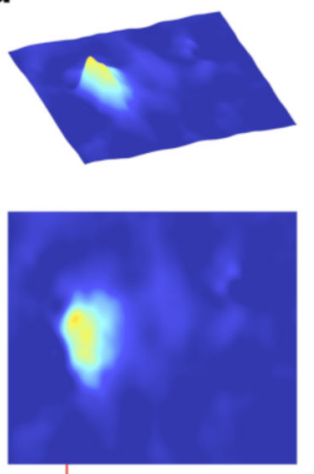

e

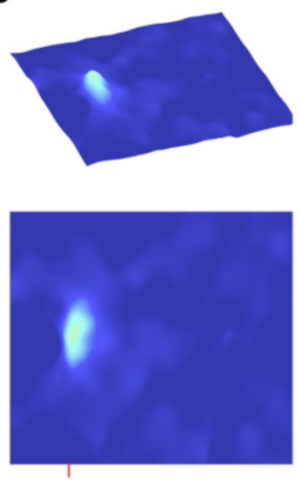

Figure 3. Localized control of $\mathrm{Ca}^{2+}$-induced $\mathrm{Ca}^{2+}$ release in cardiac myocytes using $2 \mathrm{P}$ photolysis

Single cardiac myocytes were loaded via a patch pipette with BIST-2EGTA and rhod-2. Changes in $\left[\mathrm{Ca}^{2+}\right]_{\text {free }}$ were monitored in line scan mode ( $2.116 \mathrm{~ms}$ per line) using laserscanning confocal microscopy at $561 \mathrm{~nm}$ after $2 \mathrm{P}$ uncaging at the center of the line with a mode-locked Ti:sapphire laser tuned to $810 \mathrm{~nm}$. Line scan data are displayed as 3D surface plots (time in $\mathrm{x}$, space in $\mathrm{y}$ and fluorescence as $\mathrm{F} / \mathrm{F}_{0}$ on a pseudo-color scale in $\mathrm{z}$ ) with the corresponding 2D plots (time in $\mathrm{x}$ and space in $\mathrm{y}$ ) below each 3D panel. Scale bars are 1 $\mathrm{F} / \mathrm{F}_{0}, 5 \mu \mathrm{n}$ and $50 \mathrm{~ms}$. (a) Point $2 \mathrm{P}$ irradiation with $5 \mathrm{~ms}$ pulse (red bar) triggered local $\mathrm{Ca}^{2+}$ induced $\mathrm{Ca}^{2+}$ release from the SR. (b) Photolysis of BIST-2EGTA produced highly spatially confined $\mathrm{Ca}^{2+}$ release. The cell was treated with caffeine $(20 \mathrm{mM})$ to unload the $\mathrm{Ca}^{2+}$ from the SR. (c) Increasing pulse duration to $20 \mathrm{~ms}$ initiated a $\mathrm{Ca}^{2+}$ "mini" wave, with discrete $\mathrm{Ca}^{2+}$ release events apparent beyond the initial uncaging location, (d) Reducing pulse duration to $1 \mathrm{~ms}$ produced rapid, efficient and highly localized $\mathrm{Ca}^{2+}$-induced $\mathrm{Ca}^{2+}$ release, (e) Pure photolytic release of $\mathrm{Ca}^{2+}$ from BIST-2EGTA during irradiation for $1 \mathrm{~ms}$ (cell treated with caffeine as in $\mathbf{b})$. 
a
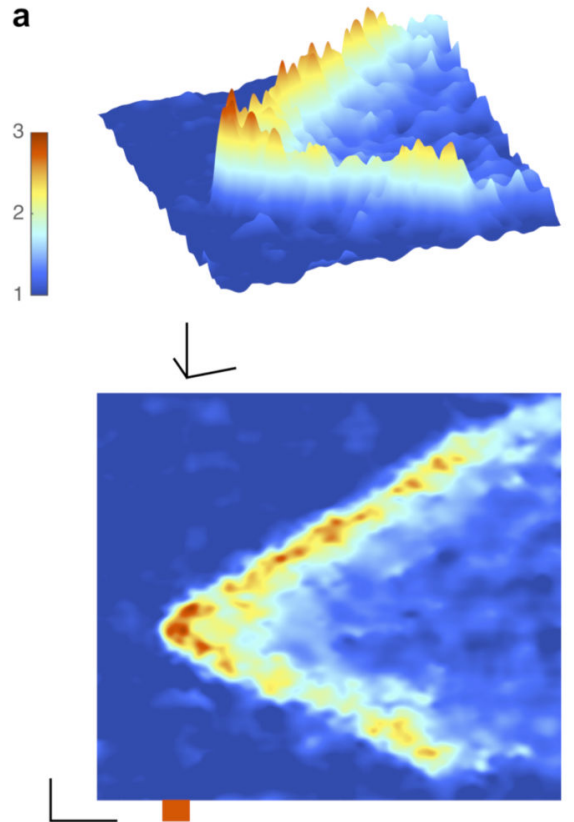

b

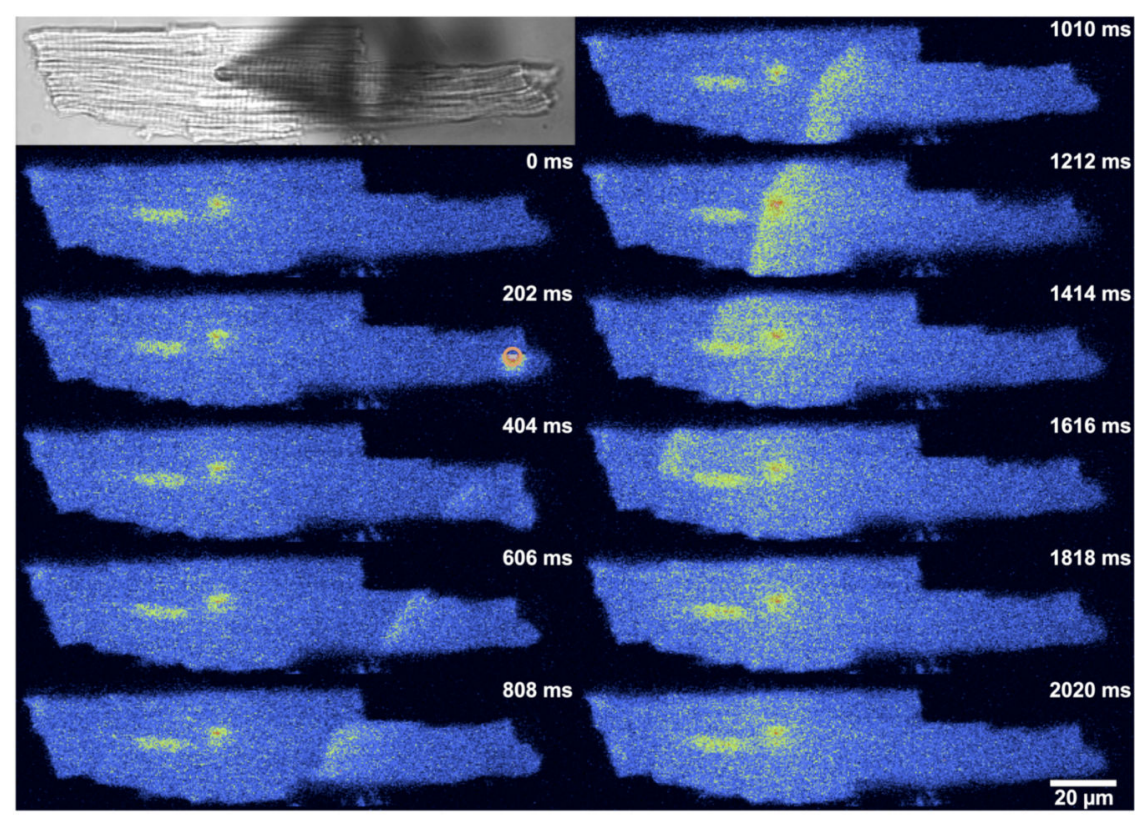

Figure 4. Visible light and 2P excitation of BIST-2EGTA: $\mathrm{Ca}^{2+}$ complex in cardiac myocytes initiates intracellular $\mathrm{Ca}^{2+}$ waves

Single cardiac myocytes were loaded via a patch pipette with BIST-2EGTA and X-rhod-5F or rhod-2. Changes in $\left[\mathrm{Ca}^{2+}\right]_{\text {free }}$ were monitored in line scan $(\mathrm{x}, \mathrm{t})$ mode $(2.116 \mathrm{~ms}$ per line) using laser-scanning confocal microscopy at $561 \mathrm{~nm}$ after $2 \mathrm{P}$ uncaging at the center of the line or by whole cell frame scan (202 ms per frame, $406 \times 96$ pixels) imaging after uncaging with visible light. A mode-locked Ti:sapphire laser tuned to $810 \mathrm{~nm}$ was used for $2 \mathrm{P}$ excitation ( $20 \mathrm{~mW}, 20 \mathrm{~ms})$. A 405-nm continuous-wave laser was used for uncaging with visible light (10 mW, $100 \mathrm{~ms})$. Line scan data are displayed as 3D surface plots (time in $\mathrm{x}$, space in $\mathrm{y}$ and fluorescence as $\mathrm{F} / \mathrm{F}_{0}$ on a pseudo-color scale in $\mathrm{z}$ ) with the corresponding $2 \mathrm{D}$ plots (time in $\mathrm{x}$ and distance in $\mathrm{y}$ ) below, (a) Rapid line scan confocal imaging revealed $2 \mathrm{P}$ excitation ( $20 \mathrm{~ms}$, red bar) could initiate $\mathrm{Ca}^{2+}$ signals that propagated extensively in both directions away from the initial uncaging position. Scale bars for units of $1 \mathrm{~F} / \mathrm{F}_{0}, 5 \mu$ and 50 ms. (b) Uncaging with visible light (orange circle) initiated a $\mathrm{Ca}^{2+}$ wave that propagated throughout the cell. Top left is a transmitted light image of the cell with the pipette seen as a shadow. Pseudocolor images represent raw fluorescence intensity data. Frame sequence is top left to bottom left, followed by top right to bottom right. The nucleus and patch pipette can be seen as bright structures in the left portion of the cell. The time stamp is from the beginning of each frame. 


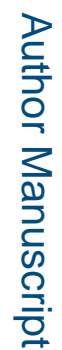

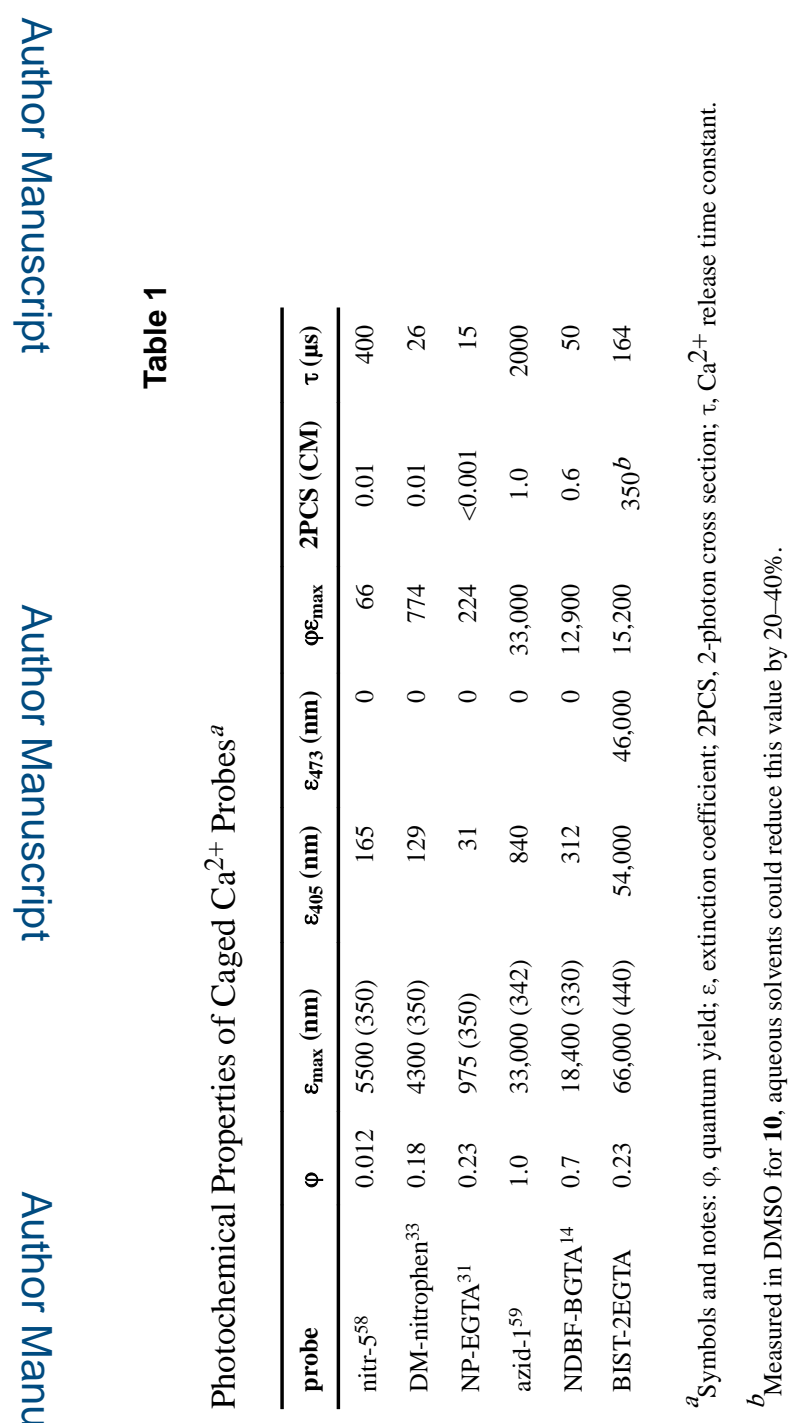

